\title{
Language, Truth, and Pedagogy
}

\author{
David Henderson $^{1}$, Dadul Namgyal ${ }^{2}$ and Mark Risjord ${ }^{3 *}$ \\ ${ }^{1}$ Department of Philosophy, University of Nebraska-Lincoln, Lincoln, NE, United States, ${ }^{2}$ Center for Contemplative Science and \\ Compassion-Based Ethics, Emory University, Atlanta, GA, United States, ${ }^{3}$ Department of Philosophy, Emory University, Atlanta, \\ GA, United States
}

Early in the planning the Emory-Tibet Science Initiative, we realized that the encounter between Buddhism and contemporary science demanded that Buddhist logic and epistemology encounter Anglophone philosophy of science. A titanic clash of world views was anticipated, but as we began the conversation, we found something different. Many philosophical concerns were shared, but these problems were understood differently. While fundamental elements of epistemology, like observation and inference, had similar functions in both traditions, subtle differences in conceptualization challenged mutual intelligibility. Through thousands of years of erudite debate, each tradition had honed their tools. While each cut cleanly, they carved in different joints. This essay will briefly discuss the linguistic, philosophical, and pedagogical adjustments that made for mutual comprehensibility.

OPEN ACCESS

Edited by:

Meena Balgopal,

Colorado State University,

United States

Reviewed by:

Linda Fuselier,

University of Louisville, United States

Alison Wallace,

Minnesota State University Moorhead,

United States

*Correspondence: Mark Risjord

mrisjor@emory.edu

Specialty section:

This article was submitted to Science and Environmental

Communication,

a section of the journal

Frontiers in Communication

Received: 18 June 2021 Accepted: 08 September 2021

Published: 15 October 2021

Citation:

Henderson D, Namgyal $D$ and Risjord M (2021) Language, Truth, and Pedagogy.

Front. Commun. 6:727488. do: $10.3389 /$ fcomm.2021.727488
Keywords: philosophy pedagogy, philosophy of science, buddhist logic, epistemology, translation

\section{INTRODUCTION}

It was afternoon, and the ceiling fans swirled the wet, pre-monsoon air through the white-walled classroom. I stood with my shirt clinging to my back, while the monks looked comfortable, sitting cross legged and attentive on their cushions. The goal of the class was to explain Popper's conception of falsifiability, wherein a hypothesis is tested by looking for circumstances where it would be false. Falsification draws its force from a form of logical inference, recognized by the ancient Greeks and known to European logicians by its Latin name, Modus Tollens. My American students had always grasped this idea quickly, so I had not prepared a lengthy explanation. Instead, I wrote my stock example on the chalkboard, intending only to remind the students of a familiar form:

If it is raining, the streets are wet.

The streets are not wet.

Therefore, it is not raining.

I was utterly dumbfounded when the monks-who were never shy about raising objections or counterexamples to what I said-refused to accept that the conclusion followed from these premises. Having written a whole book on the possibility of alternative forms of rationality, I had optimistically thought that deep problems of translation could be overcome. Now, the project of the Emory-Tibet Science Initiative seemed about to run aground on the shoals of mutual unintelligibility. After an hour and a half of intense debate, the monks remained unconvinced. I went to a bookstore in Dharmsala, purchased Stcherbatsky's two volume Buddhist Logic, and began studying.

\section{Navigating Similarities and Differences}

The foregoing events occurred while Dr. Risjord was teaching in the pilot program of Emory-Tibet Science Initiative (ETSI). Since the philosophy of science was the first subject taught in the program, 
the exchange occurred during the first contact between Emory faculty and Tibetan monastics. When planning for the ETSI, we realized that the encounter between Buddhism and contemporary science demanded that Buddhist logic and epistemology encounter Anglophone philosophy of science. We anticipated some clash of world views, and worried about incommensurability. But, happily, Dr. Risjord's experience was not the opening round of a titanic and intractable debate. We found that mutual comprehension was possible, but we faced three sources of difficulty. First, while the respective traditions engaged with closely related epistemological concerns, there were important differences in how they understood the problems. While those working in each could appreciate the kinship of their concerns, it was important for productive engagement not to gloss over these differences. Second, substantial similarities sometimes hid deeper conceptual differences. Fundamental elements of epistemology, like observation and inference, had similar functions in both traditions. But the concepts had been developed in different debates, and their consequences were subtly different. As will be developed below, the concept of validity, as opposed to soundness, while central to scientific testing, proved to be foreign to, or problematic within, Buddhist epistemology. Finally, those conceptual differences were encoded in technical philosophical terminology, which meant that translation of apparently cognate terms could be quite deceptive. To surmount these, we needed both pedagogical and translational innovations.

The point on which Dr. Risjord was stuck illustrates all three dimensions of the challenge. The monks were suspicious of Modus Tollens for two reasons. First, they doubted the truth of the first premise. After all, there are conditions when it is raining and the streets remain dry; a canopy might protect the street, for example. And without true premises, they would not grant that the conclusion followed. Second, they thought that the argument was missing a premise, or at least left something implicit in the first premise. As a form of argument, it failed to yield a valid cognition.

While there may have been some indirect contact between the earliest Indian and Greek philosophers, the Buddhist and Western logical traditions developed independently and along somewhat different lines. ${ }^{1}$ One of the differences lies in their understanding of the function of inference. What is good inference for? In the Buddhist context, good inference generates knowledge and well-constructed inferences lead to certainty. While the early Greek philosophers shared this idea, logic and epistemology began to part ways in the medieval and early modern periods of European philosophy. Mathematics

${ }^{1}$ For background on Buddhist philosophy and epistemological traditions, together with some comparisons with Western Analytic Philosophy see D’Amato, M., J. L. Garfield and T. Tillemans, Eds (2009). Pointing at the Moon: Buddhism, Logic, Analytic Philosophy. New York, Oxford University Press, Garfield (2011). Western Idealism and its Critics. Samath, Varanasi, Central University of Tibetan Studies, Westerhoff (2018). The Golden Age of Indian Buddhist Philosophy. Oxford, Oxford University Press. Also of use might be the Stanford Online Encyclopedia of Philosophy on Dharmakī, https://plato.stanford.edu/entries/ dharmakiirti/\#LogLog. developed in Europe in ways that had no parallel among Buddhist scholars, and European logic became closely associated with mathematical reasoning. This ultimately led European logicians to make a sharp distinction between validity and soundness. To say that an argument is valid is not to say that the premises are true. It is only to say that if the premises are true, the conclusion must be as well. From the European point of view, then, the falsity of the premise of Risjord's argument is beside the point when gauging its validity. On the other hand, a sound argument is one that is valid and has true premises. To be sure, only sound arguments can generate knowledge of themselves, but the soundness of an argument is not something that logic can determine. Hence, logic alone, according to European philosophers, cannot of itself produce knowledge about the world. That granted, within the Western tradition, the formal validity of an argument with a false premise could serve in a wider inquiry that did generate knowledge about the world. The point is pivotal in an understanding of scientific testing. A valid argument could not take one from true premises to a false conclusion. Thus, were one to generate a prediction about something observable by way of a valid argument with a bit of theory as a premise, one could know that, were those observations not to obtain, ... well the premises could not all be true. To the extent that one could judge that the other premises were true, one could learn of the falsity of the theory.

If good arguments are to generate knowledge, as the Buddhist philosophers hold, then a good argument must start with premises known to be true. Further, the truth of the premises must turn on non-accidental relations between the properties mentioned in the premises. (This requirement does find parallels in Western philosophy of science-although there it is associated with the idea of a good explanation rather than of a valid argument. Compare the Western philosophical idea that causal understanding turns on the properties to which one appeals actually being causally relevant, and not just correlated (the drop in mercury levels of a local barometer is not itself a causal explanation of the storm). In effect, the substantive relationship between properties-commonly a causal relationship-is of concern in Buddhist logic and Western philosophy of science, but this concern is reflected in different ways of partitioning the issues. For the Buddhist logician, it is required for good-knowledge productive-inference. For the philosopher of science, it is required for explanatory accounts, and not for logical validity (and, understandings of causation also exhibit some differences, see below).

Consider the following inference recognized by Western logicians as of the form Modus Ponens:

If there is smoke on yonder mountain, then there is fire on the mountain

There is smoke on yonder mountain

Therefore, there is fire on yonder mountain

While Buddhist logicians would agree that the presence of smoke could be a reason for thinking that there was fire on the 
mountain, they would insist that more than the form or structure of the statement seen here is important. According to Buddhist logicians, a good argument, one sufficient to produce valid cognition, must satisfy three conditions. The first two lines of the opening stanza after the verses of homage and pledge of composition in Dharmakirti's Pramanavarttika are:

The inferences that fulfill the [conditions of]

being true of the subject and the pervasions are three in types $^{2}$

First, the reason must be true-there must be smoke on the indicated mountain. Second, the proponent of the argument must specify an example, different from the case under discussion, where fire is associated with smoke, e.g., when there is smoke in the kitchen, there is necessarily fire somewhere around. An acceptable example illustrates a commitment to the necessary connection between reason and conclusion: smoke is necessarily produced from a fire (although fire may not necessarily entail smoke). Third, the reason must be restricted. The reason (the smoke) is necessarily absent in any case where what is to be proven (the fire) is also absent. The second and third conditions introduce what is called the pervasion, and they strengthen the relationship between smoke and fire so that knowledge of smoke on yonder mountain yields knowledge of fire. The remaining two lines of that same opening stanza in Dharmakirti's Pramanavarttika are:

Because they are bound in a relation of necessary pervasion [both of absence and presence].

All the remaining inferences are unsound. ${ }^{3}$

Pervasion looks to be an important place where Buddhist packaging of issues is different and yet the underlying issues may be recognized as having parallels in Western philosophy. Pervasion has to do with ideas about kinds and causes-fire causes smoke, or more fully: smoke is the kind of phenomena caused by fire, and fire is the kind of thing that causes smoke. Insofar as it is connected with ideas about causation, it also connects with two issues in scientific epistemology on which we find parallels and differences.

The first concerns knowledge of the causal connection between the relevant properties, how one can make generalizations responsive to observed patterns of covariation. In both traditions, one encounters issues about how one can be confident of the generalizability of the patterns observed. Here, Western epistemologists think of something on the order of induction. But the Buddhist tradition does not recognize inductive inference as Western philosophers and scientists do! Thus, there is both a similarity and a difference to be negotiated.

The second issue turns on the idea that there exists something on the order of a necessary truth that is rooted in the

${ }^{2}$ Dharmakirti, Pramanavirttika, chapter 1, Toh. 4210 Tengyur, tshad-ma, ce, $94 \mathrm{~b} 3$. ${ }^{3}$ Ibid., $94 \mathrm{~b} 4$. conventional, empirically inspired, concepts of smoke and fire-one might say that it is an aspect of our concepts that smoke is just the sort of particulate atmospheric emanation caused by fire, and that fire is the sort of process that, when not perfectly efficient, produces smoke. Buddhist thinking here resembles a view put forward by some Western philosophers: in the context of empirical inquiry, some concepts arise in such a way that causal connections are built into the concepts themselves (think of the conceptual interdependence of mass and force in Newtonian mechanics). The parallel here is that both traditions have reason to reflect on claims that are both empirically rooted and conceptual at the same time. But, again, to avoid an overly simple understanding of this parallel requires carefully reconstructing ideas within each tradition, rather than grabbing onto simple equivalences.

\section{RESULTING CHALLENGES OF TRANSLATION}

In the face of differing yet overlapping concerns and differing but related understanding of problems approached, the solutions hit upon within the Western and Buddhist traditions have generated different conceptualization of the elements of epistemology and logic. This makes for real challenges in mutual intelligibility: a different system of knowledge (Western science) that has developed in the context of a different evolving logic and epistemology is introduced to an audience who already has sophisticated accounts of knowledge and reasoning which evolved in yet another context with differing conceptualization and formulations. In coming to know any rich and mature system of thought, the student must manage to so reconstruct the system that they can have a sense for why one would make the connections made-in some sense mirroring or approximating an understanding "from the inside". They must appreciate how the thinker(s) formulate their problems, enabling them to recognize constraints and reason toward answers. As instructors in ETSI, we faced a pedagogical problem: how do we help students who already have sophisticated accounts of knowledge and reasoning come to understand a system of knowledge (Western science) that has developed in the context of a different logic and epistemology? Doing this well not only required us to get some interpretive purchase on the other's ways of seeing the problem, but it also required negotiating some very difficult issues of translation.

To provide a context for understanding the challenges faced, it is worth pausing to characterize the structure of the first 6 years of the ETSI program - that in which instruction was carried out by practitioners of Western science and philosophy of science

${ }^{4}$ For the author's philosophical understanding of interpretive understanding, see Henderson (1993). Interpretation and explanation in the human sciences. Albany, State University of New York Press, Risjord (2000). Woodcutters and witchcraft: rationality and interpretive change in the social sciences. Albany, State University of New York Press, Henderson (2010). "Explanation and Rationality Naturalized." Philosophy of the Social Sciences 40(1): 30-58. 
cooperatively teaming with translators. The translators were commonly monastics who themselves had recently developed Western scientific literacy. ETSI's target audience is Tibetan monastics, comprised of both monks and nuns. The monastics were engaged in the later stages of their monastic education-roughly equivalent to graduate studies within a Western education. The program consisted of six consecutive years in which about 1 month of the monastic calendar was devoted to the ETSI summer intensive program studying physics, biology, and neuroscience (each in about 1 week of courses each year). Most instructors were by college and university faculties visiting from the West. (Apart from the summer program, the monasteries have begun year-long classes in the respective scientific disciplines with their local instructors composed of both monastic graduates and lay graduated from modern universities.) Because traditional monastic education would have had sustained engagement with philosophical reflection on matters epistemological, it was thought that the philosophy of science would provide an approachable introduction into a science education. This itself made for interesting challenges, as one needed to provide potted examples of scientific work and results in order to illustrate the epistemological issues that was the course focus. The summer intensive philosophy of science course itself is about 1 week in length at the beginning of the initial year. It met in two sessions each morning, for about $3 \mathrm{~h}$ of structured presentation. This was followed each afternoon with sessions in which the monastics would pose questions, resulting in commonly lively discussion. Particularly in these afternoon sessions, instructors and translators were able to get a reasonable purchase on how well the instruction was coming across. It should also be noted that in a recent webinar with some 60 monastics who had completed the course of study, graduates proved able to trace a number of differences and continuities between the philosophy of science and Buddhist philosophy. They were sensitive to the differences in understandings of inferential knowledge and of relevant presumptions of the respective traditions. (The graduates participating in these sessions did the same for the other disciplines that are the focus of ETSI as well.)

Instructors confronted an unusual challenge from the outset: the instruction must take place in a language foreign to many of the monastics-English-and be brought home to the monastics via translation into Tibetan. With no prior precedent for teaching modern science to a Tibetan audience in any form, let alone in a sustained and comprehensive manner as ETSI, that also meant having to improvise Tibetan equivalents for the technical terms and foreign concepts being encountered as the instruction progresses. This pedagogical challenge increased when it came to the philosophy of science. The monastics who enrolled for the program would already have had no less than 10 and as many as 15 years of rigorous training and engagement in philosophy and metaphysics through the medium of their own sophisticated and well-developed system of logic and epistemology. Unless great care is taken in translation, the sophisticated training of the monastics could add to the challenges instead of mitigating them. (Happily, going forward instruction will be carried on by a devoted staff at the monasteries who themselves have lived the challenges in a way that equips them to as the interlocutors in this exchange of concepts and traditions).

Translation must be undertaken so as not to tempt the students with a false understanding of the claims advanced in the course. Wanton translation would either assimilate the scientific epistemology and logic in a way that would reassuringly erase differences, or (ultimately) would treat each tradition as doing the same thing-engaged in straightforwardly the same epistemic projects and problems-but each would see the other as doing so in a ham-fisted way, unresponsive to obvious problems. Given the situation, those presenting the material have a special responsibility in facilitating the delivery and enhancing mutual understanding, not contributing to the confusion. Much of this burden fell upon those members of the presenting team who were most qualified to be responsive: the translators found themselves facing a delicate and demanding task. Happily, the translators both happen to be adequately trained in the traditional Buddhist system of education and had English language skills for comprehension and conveyance of the Western knowledge system. With ready access to the Western professors, they could pursue clarification and perspectives, and did so both in and out of class. Notably, they did not come to this role as translator in class without the benefit of much preparation. They were attentive to the differences between the traditions evidenced in pre-course study of the subject matter and their pre-lesson preparations-additionally, most translators had been responsible for the translation of textbooks, lesson slides, and notes. As a result, these translators were alive to the subtle and nuanced differences in the understandings and approaches of the two traditions. So much so that they were alive to this delicate challenge: readily borrowing technical terms from Buddhist sources in conveying concepts and notions from Western traditions was recognized to be off-limits-as the Buddhist technical terms were recognized as potentially engendering unnecessary mutual puzzlement and confusion instead of aiding in comprehension and intelligibility.

So, how did the translators approach their responsibility? To the extent required and possible, they strove for new terms for the novel concepts that the monks needed to grasp. Presenting the concepts in these new terms highlighted the novelty of the concepts being conveyed and the essential distance in their implications from those of the already familiar concepts or notions in Buddhist system. For example, the translations convey "induction" and "deduction" in totally new expressions, even though it meant coming up with a phrase for each instead of a convenient single term. The translation team has yet to settle on convenient single-term equivalents that would be both palatable to the students and sufficiently representative of the source terms. Though far from a satisfactory rendition, the current expressions in Tibetan capture some common features of those reasonings as practiced in Western tradition. Admittedly, even this characterization covers only a partial truth about the inferences in the Western tradition and thus warrants further improvement, which the translators are always open to explore. However, it is far safer and more convenient way of handling them for the time being. It minimizes the risk of confusion and 
puzzlement arising out of conveniently simple, but distorting, equivalences.

Similarly, while there are ideas in the Western traditions of scientific practice and philosophy of science that bear crosscutting and partial parallels to the notion of pervasion within Buddhist epistemology, our translators have shied away from using the Buddhist term for pervasion as a translation for any term in the Western tradition. This is again because, aside from the superficial similarity, there is a marked difference in the actual form and significance of the respective traditions.

Another example of carefully negotiating the choice of words in translation is for the terms "realism" and "antirealism." Given that the whole of Buddhist thought is systematically geared towards establishing the primacy of mind over matter, subjective as opposed to objective, there is no dearth of established terms to choose from and made use of. That includes compact technical terms used for connoting the "absence of objective world external to consciousness" as advocated by the Mind-only school, or the more popularly acknowledged terms connoting the "absence of inherently, truly, intrinsically existent phenomena," as proposed by the Middle-way school in Buddhism. That would have been an easy choice and still capture the intended partial meaning in the Western tradition, but at the risk of creating confusion and naive associations on the part of the students. Instead, the translators created a hybrid term that leaves the students at a loss to make ready associations, and instead makes them wonder about the actual intended meaning behind the novel terms, hopefully ultimately leading to a better understanding of the

\section{REFERENCES}

M. D'Amato, J. L. Garfield, and T. Tillemans (Editors) (2009). Pointing at the Moon: Buddhism, Logic, Analytic Philosophy (New York: Oxford University Press).

Garfield, J. L. (2011). Western Idealism and its Critics. Sarnath, Varanasi: Central University of Tibetan Studies.

Henderson, D. (1993). Interpretation and Explanation in the Human Sciences. Albany: State University of New York Press.

Henderson, D. (2010). Explanation and Rationality Naturalized. Philos. Soc. Sci. 40 (1), 30-58. doi:10.1177/0048393109350680

Risjord, M. (2000). Woodcutters and Witchcraft: Rationality and Interpretive Change in the Social Sciences. Albany: State University of New York Press.

Westerhoff, J. (2018). The Golden Age of Indian Buddhist Philosophy. Oxford: Oxford University Press. original source. Unlike the sciences, which are new and unfamiliar to the monastics, translating for the philosophy of science keeps one on the alert all the time and always making sure one thinks twice before ever deciding to use an already loaded term.

Europeans have often imagined situations of mutual unintelligibility and wonder how communication would be possible. Our experience with teaching the philosophy of science to Tibetan monastics shows that the really difficult problems arise not from total unintelligibility, but from partial intelligibility. These problems can be surmounted, but they require patient attention to both tiny nuances of meaning and grand differences of perspective. ETSI has inaugurated a significant project with a long horizon, and we can only hope that future generations of monastics and European-trained philosophers keep the conversation alive.

\section{DATA AVAILABILITY STATEMENT}

The original contributions presented in the study are included in the article/Supplementary Material, further inquiries can be directed to the corresponding author.

\section{AUTHOR CONTRIBUTIONS}

All authors listed have made a substantial, direct, and intellectual contribution to the work and approved it for publication.

Conflict of Interest: The authors declare that the research was conducted in the absence of any commercial or financial relationships that could be construed as a potential conflict of interest.

Publisher's Note: All claims expressed in this article are solely those of the authors and do not necessarily represent those of their affiliated organizations, or those of the publisher, the editors and the reviewers. Any product that may be evaluated in this article, or claim that may be made by its manufacturer, is not guaranteed or endorsed by the publisher.

Copyright (c) 2021 Henderson, Namgyal and Risjord. This is an open-access article distributed under the terms of the Creative Commons Attribution License (CC BY). The use, distribution or reproduction in other forums is permitted, provided the original author(s) and the copyright owner(s) are credited and that the original publication in this journal is cited, in accordance with accepted academic practice. No use, distribution or reproduction is permitted which does not comply with these terms. 